\title{
A EFICIÊNCIA DO GASTO TRIBUTÁRIO E A UTILIZAÇÃO DAS POLÍTICAS DE RENÚNCIA FISCAL NA CULTURA
}

\section{THE EFFICIENCY OF TAX EXPENDITURE AND THE USE OF FISCAL WAIVER POLICIES IN CULTURE}

\section{CACIA CAMPOS PiMENTEL ${ }^{1}$}

RESUMO: O artigo pretende explicar o mecanismo de financiamento das políticas públicas de renúncia fiscal no Brasil. Objetiva verificar a qualidade do gasto público e a efetividade da utilização dessas políticas, sob a ótica do Direito Constitucional Econômico, para permitir ajustes na alocação dos recursos públicos. Na Parte I, o estudo busca compreender o enquadramento legal da renúncia fiscal como instrumento de fomento ao dinamismo econômico para a diminuição das desigualdades, desde que integrada corretamente no orçamento fiscal, para melhor efetividade dos gastos e consecução dos seus objetivos. Demonstra, ainda, a divergência conceitual da legislação pátria em comparação com o entendimento adotado por organismos públicos nacionais e internacionais. Na Parte II, o estudo apresenta uma breve exegese dos pensamentos liberal e desenvolvimentista sobre o tema, para que a justaposição dessas correntes auxilie na demonstração das falhas nos gastos tributários e da evolução das políticas públicas. A Parte III, com foco no setor da Cultura, aborda a análise das prestações de contas e da utilização dos recursos públicos com base na Lei Rouanet. Os dados permitem afirmar que os objetivos constitucionais da política de renúncia fiscal não estão sendo alcançados. Como conclusão, o estudo apresenta sugestões. Para que haja uma eficiente alocação dos recursos públicos, a renúncia fiscal precisa ser considerada como mecanismo excepcional e temporário para corrigir distorções econômicas e sociais regionalizadas. Assim, deve-se evitar que haja uma centralização dos recursos públicos onde há dinamismo econômico, em favor de outras regiões que ainda não apresentam desenvolvimento econômico significativo.

\footnotetext{
${ }^{1}$ Doutoranda em Direito Político e Econômico pela Universidade Presbiteriana Mackenzie, São Paulo (Bolsa Mérito). Mestre em Direito pela Cornell University, New York (revalidação como Mestre em Direito pela Universidade de Brasília). MBA em Direito Econômico e das Empresas pela FGV-DF. Graduada em Direito pela Universidade de Brasília-UnB. Pesquisadora na Cornell University de junho/2007 a junho/2009, nas áreas de contratos internacionais e empresariais, arbitragem internacional e OMC. Currículo Lattes: http://lattes.cnpq.br/5669016828483675. Contato: caciapimentel2012@gmail.com.
} 
Palavras-Chave: Gastos públicos; Gastos tributários; Políticas públicas; Renúncia fiscal; Direito Econômico.

ABSTRACT: The article aims to explain the financing mechanism of tax exemption policies in Brazil. It aims to verify the quality of public spending and the effectiveness of the use of these policies, from the point of view of the Economic Constitutional Law, to allow adjustments in the allocation of public resources. In Part I, the study seeks to understand the legal framework of fiscal renunciation as an instrument to foster economic dynamism in order to reduce inequalities, provided that it is correctly integrated into the fiscal budget, so that expenditures are more effective, and the objectives achieved. It also demonstrates the conceptual divergence of national legislation compared to the understanding adopted by national and international public bodies. Part II presents a brief exegesis of the liberal and developmental thoughts on the subject in order to demonstrate the failures of tax expenditures and the evolution of public policies. Part III focuses on the Culture sector and its accountability. The analysis of the public expenditure based on the Rouanet Law make it possible to affirm that the constitutional objectives of the fiscal renunciation policy are not being achieved. As a conclusion, the study presents suggestions. For an efficient allocation of public resources, tax exemption should be considered as an exceptional and temporary mechanism to correct regionalized economic and social distortions. Thus, public agents should avoid centralizing public resources where there is economic dynamism, in favor of other regions that do not yet have significant economic development.

Keywords: Public spending; Tax expenditure; Public Policies; Tax Exemption; Economic Law.

\section{INTRODUÇÃO}

Os dados econômicos oficiais mais recentes demonstram que os formuladores de políticas públicas, no ano em que a Constituição Federal celebra 30 anos de sua promulgação, necessitam pausar, monitorar e avaliar os resultados da atual forma de utilização do mecanismo constitucional da renúncia fiscal como instrumento de desenvolvimento socioeconômico. Para esse fim, o presente trabalho apresenta algumas concepções teóricas centrais para se compreender o papel do Estado e da renúncia fiscal como instrumento de intervenção econômica. Em seguida, serão 
apresentados os dados econômicos mais recentes e, ao final, deverá se verificar em que medida as políticas públicas de renúncia fiscal têm sido efetivas para fomentar o desenvolvimento econômico e social e em que medida elas têm relação com o desequilíbrio das contas públicas.

Qual o tipo de envolvimento que o Estado deve ter com o mercado? Peggy e Richard Musgrave (1980) já destacavam as dificuldades de se tirar de uns para melhorar a situação de outros ou de se utilizar as receitas tributárias para promover ajustes na alocação dos recursos. No desempenho de suas atribuições econômicas, cabe ao Estado subsidiar e fomentar setores econômicos específicos? Ou ainda, deve o Estado controlar as consequências da concentração financeira, regulando $o$ desemprego, a falta de moradia, a infraestrutura básica e oferta de saúde e educação?

A participação do Estado é axiomática, a discussão situa-se na forma e no grau dessa intervenção. E de igual importância é a verificação da qualidade do monitoramento, da prestação de contas e da responsabilização sobre os investimentos feitos com recursos públicos. Para os liberais, a lógica do intervencionismo é o Estado investir onde o mercado não se interessa, ou seja, o Estado deve estar pautado no interesse público. Eles entendem que intervenções erradas podem destruir ou trazer graves abalos a empresas, como ocorreu com a recente crise na Petrobrás, por exemplo. Para os desenvolvimentistas, a intervenção do Estado deve ir além da correção das falhas de mercado, para promover o desenvolvimento econômico com o fim de alcançar proteção e inclusão social, para a diminuição de desigualdades.

Destarte, é premente a necessidade de se debater a relação entre o mercado - onde nasce e circula a riqueza - e o Estado, o qual pode adotar medidas de incentivo fiscal com o fim de fomentar o crescimento econômico. Igualmente importante, é aprender a integrar as políticas públicas para uma maior efetividade de seus resultados.

O objetivo desse trabalho é verificar a qualidade do gasto público e a efetividade da utilização das políticas públicas de renúncia fiscal no país, sob a ótica do Direito Constitucional Econômico. Nesse passo, os conceitos tributários, orçamentários e econômicos serão utilizados apenas na medida necessária para se compreender o instituto da renúncia fiscal, em uma abordagem jurídico-econômica.

A metodologia qualitativa e quantitativa utilizada permite a revisão da literatura nacional e estrangeira associada ao tema, além dos dados oficiais providos pelos órgãos públicos, de modo a utilizar o arcabouço jurídico e documental e explorar os arranjos institucionais e suas formas de interação.

Portanto, o presente estudo desenvolve-se da seguinte forma. Na Parte I, busca-se compreender o enquadramento legal da renúncia fiscal como instrumento de fomento ao dinamismo econômico para a diminuição das desigualdades, de modo a se agregar corretamente o mecanismo no orçamento fiscal e exigir melhor efetividade dos gastos e consecução dos seus objetivos. A Parte II apresenta uma breve exegese dos 
pensamentos liberal e desenvolvimentista sobre o tema, para que a justaposição dessas correntes auxilie na demonstração das falhas nos gastos públicos e da evolução das políticas públicas direcionadas ao setor da Cultura. Ao final, o estudo apresenta conclusões e sugestões.

\section{ENQUADRAMENTO LEGAL DA RENÚNCIA FISCAL}

As políticas públicas econômicas de renúncia fiscal devem servir para fomentar a economia, especialmente diminuindo as desigualdades regionais. No entanto, podem existir ineficiências na utilização dessas políticas que precisam ser identificadas. Para que se possa compreender os entraves das políticas de renúncia fiscal, é preciso compreender, primeiramente, os diferentes conceitos e formas de utilização desse mecanismo, pois o modelo escolhido pelo país influirá na estrutura legal e na forma de enquadramento da renúncia no sistema tributário de referência.

Alguns países entendem a renúncia fiscal como benefício tributário, outros classificam como gasto público, outros como gasto tributário. Países ligados à Organização para Cooperação e Desenvolvimento Econômico (OCDE) entendem que a renúncia fiscal é um tipo de despesa governamental na forma de gasto tributário, uma vez que o Estado deixa de coletar receitas legitimamente devidas, portanto, passíveis de rígido controle orçamentário (OCDE, 2009).

Para o Fundo Monetário Internacional (FMI), as renúncias fiscais (FMI, 2007)

Consistem em receita que se deixa de arrecadar como resultado de dispositivos específicos do código tributário. Entre os possíveis tipos destacam-se as isenções da base tributária, deduções da renda bruta, créditos contra o imposto a pagar, reduções de alíquotas e o diferimento do imposto a pagar (por ex., por meio de depreciação acelerada). Não raro são usadas em substituição a programas explícitos de gastos orçamentário.

Por sua vez, o Banco Mundial esclarece que a renúncia fiscal é uma provisão fiscal que se desvia do sistema tributário de referência e que pode se manifestar sob várias formas de gastos tributários, como exclusões, renúncias, subsídios, deduções, créditos fiscais, taxas preferenciais e diferimentos. ${ }^{2} \mathrm{O}$ Banco Mundial explica que todos os incentivos fiscais são desenhados para mudar o comportamento do mercado de modo

${ }^{2}$ A Receita Federal não considera diferimento um gasto tributário, por entender que não constitui redução dos tributos devidos, pois haverá compensação futura, por exemplo, nos casos de parcelamentos de dívidas tributárias, mudanças de prazos de pagamento e as compensações de bases negativas. 
a alcançar alvos econômicos e sociais específicos (BANCO MUNDIAL, 2006). Assim, os incentivos devem ser temporários e monitorados para a verificação de sua efetividade e alcances desses alvos. Isso porque os incentivos fiscais, por serem gastos, diminuem a receita pública e dificultam o equilíbrio fiscal, aumentando o déficit ou diminuindo o excedente.

O artigo 165, parágrafo 6º da Constituição Federal, estabelece a obrigação do Poder Executivo apresentar demonstrativo regionalizado do efeito, sobre as receitas e despesas, decorrente de isenções, anistias, remissões, subsídios e benefícios de natureza financeira, tributária e creditícia. A Lei de Responsabilidade Fiscal estabelece, no art. $5^{\circ}$, inciso II, que o projeto de lei orçamentária anual (LOA) deverá conter o demonstrativo a que se refere o artigo 165 , parágrafo 6 , além das medidas de compensação de renúncias de receita e do aumento de despesas obrigatórias de caráter continuado.

Essa mesma lei define a renúncia fiscal como um benefício de natureza tributária (art. 14) que compreende "anistia, remissão, subsídio, crédito presumido, concessão de isenção em caráter não geral, alteração de alíquota ou modificação de base de cálculo que implique redução discriminada de tributos ou contribuições, e outros benefícios que correspondam a tratamento diferenciado" $\left(\$ 1^{\circ}\right)$.

O Tribunal de Contas da União (TCU), na linha dos países da OCDE, adota a concepção da renúncia fiscal como um desvio de um sistema tributário de referência, ou seja, um gasto tributário indireto, um transvio excepcional da estrutura tributária matriz, na qual constam as regras que determinam a obrigação tributária (BRASIL, 2010). O fim desse gasto tributário deve ser atender a objetivos econômicos e sociais, aumentando a disponibilidade econômica do contribuinte.

A Receita Federal entende que gastos tributários são "gastos indiretos do governo realizados por intermédio do sistema tributário, visando a atender objetivos econômicos e sociais e constituem-se em uma exceção ao sistema tributário de referência, reduzindo a arrecadação potencial e, consequentemente, aumentando a disponibilidade econômica do contribuinte" (BRASIL, 2017b).

Convém diferenciar o conceito de gasto público do conceito de gasto tributário, muitas vezes erroneamente intercambiados. O gasto público, também chamado de despesa pública, é aquele que integra a base orçamentária, ou seja, é uma despesa orçamentária que demonstra a realização das finalidades do Estado, no atendimento das necessidades da coletividade (PALUDO, 2015, p. 195). Diferentemente, o gasto tributário, onde se inclui a renúncia de receitas, não constitui a base orçamentária no Brasil, embora haja recomendação dos organismos internacionais no sentido de incluir o gasto tributário no orçamento para submetê-lo a um controle regular da utilização desses recursos. Em consideração ao princípio da prudência, os países com alta renda 
per capita ${ }^{3}$ tomam medidas de precaução na utilização desses gastos, verificando a qualidade de seus resultados e o melhor momento para a emancipação dos setores beneficiados (BANCO MUNDIAL, 2006).

Diante desses parâmetros conceituais, como tem sido a distribuição regionalizada desses gastos? E qual tem sido o resultado dos gastos tributários, mormente a renúncia fiscal, ou seja, qual tem sido a receita gerada pela utilização dessa forma de fomento econômico?

Conforme dados da Receita Federal (BRASIL, 2017b), sob a ótica orçamentária, os gastos tributários na forma de renúncia fiscal em 2017 somaram $\mathrm{R} \$ 284,85$ bilhões, com concentração dos gastos tributários de 51,6\% na região Sudeste e de 16,6\% na região Sul.

Tabela 1. Gastos tributários - Projeções PLOA 2018 - Consolidação por função orçamentária (unidade: $R \$ 1,00$ )

\begin{tabular}{l|r|r|}
\hline \multicolumn{1}{|c|}{ FUNÇÃo ORÇAMENTÁRIA } & VALOR & \multicolumn{1}{c|}{$\%$} \\
\hline Comércio e Serviço & 80.760 .435 .573 & $28,49 \%$ \\
Trabalho & 43.390 .065 .284 & $15,31 \%$ \\
Saúde & 39.024 .430 .643 & $13,77 \%$ \\
Indústria & 31.927 .247 .635 & $11,26 \%$ \\
Agricultura & 26.848 .974 .019 & $9,47 \%$ \\
Assistência Social & 14.134 .279 .541 & $4,99 \%$ \\
Educação & 13.189 .843 .726 & $4,65 \%$ \\
Habitação & 10.728 .942 .263 & $3,79 \%$ \\
Ciência e Tecnologia & 10.207 .324 .015 & $3,60 \%$ \\
Transporte & 5.004 .474 .552 & $1,77 \%$ \\
Energia & 4.002 .080 .886 & $1,41 \%$ \\
Cultura & 1.765 .138 .205 & $0,62 \%$ \\
Direitos da Cidadania & 1.541 .229 .025 & $0,54 \%$ \\
Desporto e Lazer & 501.033 .672 & $0,18 \%$ \\
Administração & 299.239 .830 & $0,11 \%$ \\
Defesa Nacional & 72.110 .718 & $0,03 \%$ \\
Organização Agrária & 43.730 .193 & $0,02 \%$ \\
Comunicações & 2.146 .971 & $0,00 \%$ \\
Saneamento & 2.141 .321 & $0,00 \%$ \\
Gestão Ambiental & 1.861 .305 & $0,00 \%$ \\
\hline \multicolumn{1}{|c|}{ TOTAL } & $\mathbf{2 8 3 . 4 4 6 . 7 2 9 . 3 7 8}$ & $\mathbf{1 0 0 \%}$ \\
\hline
\end{tabular}

Fonte: Ministério da Fazenda, 2018.

${ }^{3}$ Segundo o Banco Mundial, são países com renda per capita acima de USD 12,235. 
No exercício de 2018, a previsão dos gastos tributários é de $\mathrm{R} \$ 283,44$ bilhões e apontou uma concentração de $78,30 \%$ do valor dos gastos em cinco funções orçamentárias de governo, são elas: Comércio e Serviço com 29,49\%; Trabalho com 15,31\%; Saúde com 13,77\%; Indústria com 11,26\%; e Agricultura com 9,47\%.

A renúncia fiscal é uma intervenção estatal indutora sobre o domínio econômico, ou seja, o Estado oferece incentivos fiscais por meio de preceitos normativos, de modo a induzir o mercado a investimentos em determinadas regiões ou setores da economia. As políticas econômicas que adotam esse mecanismo são concedidas em regra mediante lei específica e devem ser periodicamente reavaliadas, de modo a verificar se estão efetivamente alcançando as metas e os objetivos originalmente estabelecidos. Dependendo do resultado do monitoramento e do controle, as políticas públicas poderão ser cessadas ou modificadas.

Para o FMI, as renúncias fiscais

podem também ser direcionadas para tipos específicos de gastos ou categorias específicas de indivíduos, famílias ou empresas de acordo com o seu patrimônio, nível de renda, padrão de gastos ou outras características. Em muitos sistemas tributários, as renúncias fiscais podem ser significativas em comparação com o total da receita tributária. Uma diferença importante em relação aos programas de gastos é que as renúncias fiscais não requerem aprovação anual formal pelo legislativo (embora possam estar sujeitas a cláusulas de caducidade). Além disso, são válidas enquanto a lei tributária não for alterada e, por conseguinte, raramente são submetidas ao mesmo grau de escrutínio que as despesas efetivas. Portanto, uma proliferação de renúncias fiscais pode resultar numa grave perda de transparência (FMI, 2007, itálico meu).

Com efeito, o artigo 70 da Constituição Federal estabelece que o papel de fiscalização da aplicação das subvenções e renúncias de receitas deve ser exercido primariamente pelo Congresso Nacional mediante controle externo e, ainda, pelo sistema de controle interno de cada poder.

No entanto, conforme se verá nos exemplos apresentados adiante, os sistemas de prestação de contas e de responsabilização legal carecem de efetividade e integração, para se monitorar e avaliar os resultados dos investimentos dos recursos públicos feitos pelo setor privado, para verificar os resultados atingidos, a necessidade de correção de rumos ou a possibilidade de emancipação do setor subsidiado. É importante que se estabeleçam métricas que permitam avaliar a eficiência, eficácia e efetividade da qualidade desses gastos tributários, pois é isso que permitirá uma correta adoção de políticas públicas que ajudem a diminuir a altíssima concentração de renda. 
De acordo com o Relatório do Governo Federal sobre os gastos tributários, denominado $2^{\mathrm{o}}$ Orçamento de Subsídios da União, divulgado em maio 2018 (Ministério da Fazenda, 2018), a Emenda Constitucional n 95/2016, ao instituir o teto dos gastos, diminuiu o espaço para ampliação de despesas orçamentárias (BRASIL, 2017a). Com isso, há uma pressão pelo aumento dos gastos tributários como instrumento de fomento a setores ou atividades, à margem do controle do "teto dos gastos". Uma vez que no Brasil não compõem o orçamento, os gastos tributários aparecem como uma alternativa para se esquivar das imposições da emenda constitucional.

O relatório assinala ainda que

o elevado patamar de gastos tributários demonstra a necessidade de implementação de mecanismos de controle, transparência e avaliação, sob um prisma de materialidade e relevância, para que se reporte à sociedade os resultados efetivos dessa categoria de subsídios, [...] implantar maior rigor na concessão de gastos tributários e concluir a ação interministerial em curso que visa instituir Comitê de Monitoramento e Avaliação dos Subsídios (CMAS), com vistas a permitir que a recente trajetória de redução dos subsídios permaneça ao longo do tempo.

Observe-se, no entanto, que mais do que perquirir a redução dos subsídios, caberia analisar a efetividade da utilização desse instrumento de política pública, com o fim de utilizá-lo para fomentar o crescimento econômico, em respeito, entre outros, ao art. 257 do Regimento Interno do TCU. Além disso, é essencial que se adote mecanismo de rastreamento da aplicação do dinheiro dos impostos. Conforme aponta Mazzucato (2015, p. 189), "o sucesso aumenta as probabilidades de apoio a outra rodada de investimentos e gera mais visibilidade para o papel positivo que o governo pode ter" ao promover uma política de fomento.

O Estado brasileiro dificulta ainda mais esse processo ao não manter um controle do resultado dos gastos tributários sobre o PIB, ou seja, não se desenvolvem métricas e indicadores para a avaliação da receita gerada pela utilização dessa forma de fomento econômico, para se calcular o impacto da política econômica antes e depois da lei que a instituiu. Em outras palavras, é imprescindível a verificação das séries históricas para comprovar o reflexo das políticas de renúncia fiscal sobre certas funções orçamentárias, comparando o resultado dos gastos tributários em favor de alguns setores e o impacto sobre o PIB, antes e depois da adoção da política. O próprio TCU entende que são poucos os órgãos que efetuam avaliação dos resultados das políticas públicas que utilizam o mecanismo da renúncia fiscal. Na maioria dos casos 
faltam os requisitos mínimos de um desenho de política pública, como, por exemplo, indicadores e metas (BRASIL, 2014a). Na verdade, 42,3\% das renúncias permanecem sem órgão gestor responsável identificado.

Figura 1. Gestão da renúncia fiscal (razões percentuais)

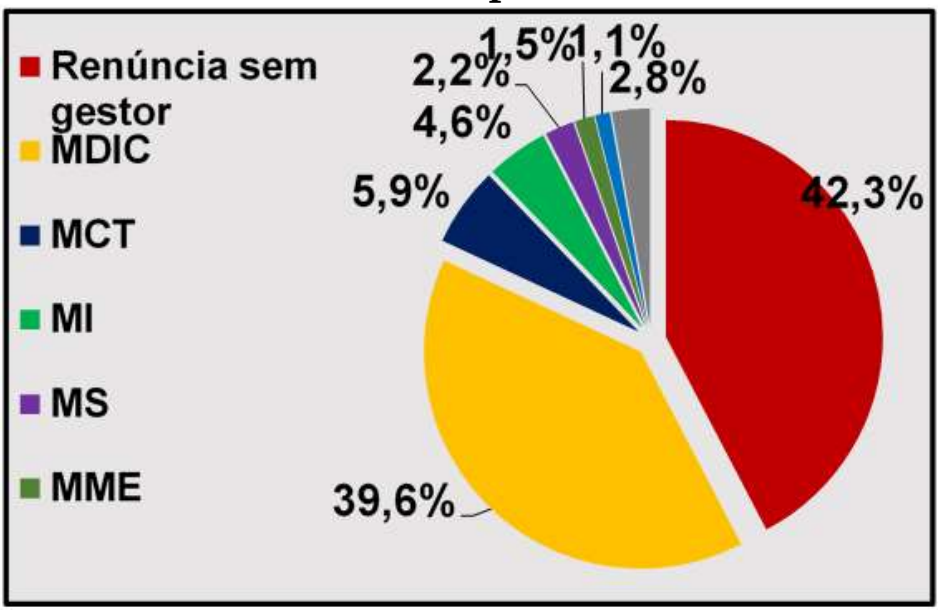

Fonte: TCU, 2018

Sob outro ângulo, registre-se a dificuldade que o Estado demonstra na utilização de seu poder de compra para incentivar a inovação e o desenvolvimento de novas tecnologias, como alternativa à utilização da renúncia fiscal. Em recente estudo promovido pelo Centro de Gestão e Estudos Estratégicos (CGEE), organização social supervisionada pelo Ministério da Ciência, Tecnologia e Inovação (MCTI), em parceria com os professores Mariana Mazzucato e Caetano Penna, apontou-se que as ineficiências no sistema exigem uma reforma no complexo sistema tributário e a remoção de barreiras ao poder de compras públicas, de modo a permitir que sejam orientadas a encomendas específicas para a área de inovação, tecnologia, entre outros. O estudo concluiu que uma agenda de políticas orientadas por missões aumentaria a eficácia das políticas de inovação do Brasil, permitindo o reequilíbrio das finanças públicas, não só por meio do corte de gastos, mas pelo aumento dos investimentos estratégicos (BRASIL, 2016b).

\section{PARTE II - Pensamentos liberal E Desenvolvimentista: ANÁlise DA EFETIVIDADE DA RENÚNCIA FISCAL}

Não existe livre mercado sem leis e a intervenção do Estado. Para que se compreenda essa afirmação, Karl Polanyi (2000, p. 171-172) sugere a observação dos fatos ocorridos desde o século XVIII e da rápida transformação dos cenários 
econômicos e sociais a partir do século XIX. As desigualdades acentuadas em função da industrialização tornaram necessária a atuação do Estado em duas frentes: para a implantação de normas que instituíssem os pilares do liberalismo e, ainda, para diminuir a pobreza absoluta por meio de políticas distributivas.

O autor descreve uma relação de movimento (expansão do mercado) e de contra movimento (comportamento defensivo da sociedade e da regulação estatal). O choque entre os princípios organizadores do liberalismo econômico e a ausência de proteção social conduziram os conflitos institucionais a um ápice. O princípio organizador do sistema de mercado foi o liberalismo econômico. A partir do século XIX, o liberalismo passou a representar o trabalho precificado pelo mercado, o comércio livre de bens e serviços e um mecanismo de padronização da moeda. Essas transformações só foram possíveis pela forte intervenção do Estado, de forma contínua, controlada e centralizada.

Polanyi deixa claro que não existe livre mercado sem o Estado impor as regras do jogo, como por exemplo regras sobre a propriedade, a concorrência, os contratos, a falência e mesmo sobre os procedimentos à execução. Para ilustrar, vejam-se as normas de falência. Elas permitem que o empresário usufrua das garantias e prazos oferecidos para recuperação judicial. No entanto, essas proteções não são extensíveis a grupos que exercem menor pressão sobre os agentes políticos, como devedores de créditos estudantis ou devedores de crédito imobiliário que precisem se reorganizar para o pagamento de dívidas durante crises do mercado imobiliário.

Assim, percebe-se a atuação do Estado para garantir as bases liberais que geram e multiplicam a riqueza e para fornecer serviços e bens públicos. Esse ciclo ocorre por meio de um trade off macroeconômico, em que o Estado cobra os impostos para compor sua receita e redistribui para grupos de interesse, condicionado a fatores políticos, sociais e do próprio mercado. A falta de equilíbrio dessas condicionantes pode gerar inflação, restrições externas e déficit público (GIAMBIAGI; ALÉM, 2011, p. 357).

Os defensores do liberalismo justificam as falhas no sistema liberal pela intervenção incorreta do Estado na implantação de seus princípios. Alegam alguns liberais, segundo Polanyi, que o protecionismo foi um erro resultante da impaciência, ambição e estreiteza de visão, e sem elas o mercado teria resolvido suas dificuldades. $\mathrm{O}$ autor, em sua tese do duplo movimento, concorda que o movimento liberal, na difusão do sistema de mercado, sofreu um contra movimento protetor que se empenhava em restringi-lo. Mas Polanyi defende que um mercado completamente auto regulável teria destruído a sociedade.

O contra movimento pode ser observado nos normativos que buscam estabelecer um macroambiente econômico equilibrado, com base em tomadas de decisão pautadas 
na ética, que possam ser consideradas politicamente escorreitas e que garantam a inclusão econômica sem comprometer o próprio crescimento econômico.

No contra movimento, os regulamentos deveriam ser elaborados e as condutas econômicas fiscalizadas por agências públicas. A agência é concebida para ser dotada de um corpo técnico preparado para tomar as decisões. No entanto, essas pessoas são especialistas da área e que, ao fim do mandato, poderão ser capturadas pelas empresas fiscalizadas. A criação da agência reguladora e as normas do setor são feitas pelo Legislativo. O pior cenário é certamente o da criação de uma agência reguladora com legislação já influenciada pela captura em sua edição. No entanto, a centralização do sistema demonstra ser um cenário ainda pior. O que ocorre no Brasil é o aparelhamento das agências por meio de escolhas políticas dos seus dirigentes.

As contribuições de campanha política, campanhas de marketing e institutos de pesquisa, podem produzir relatórios com informações filtradas que se coadunem com os interesses dos grupos econômicos, influenciando procedimentos judiciais, regulatórios, audiências públicas, gabinetes parlamentares. Assim, o poder de captura acaba por produzir um forte desequilíbrio nas relações econômicas.

Tome-se, por exemplo, o setor financeiro mundial. Atualmente, o capitalismo é capitaneado pelo setor financeiro, que viabiliza a acumulação não só do capital, mas o poder político e jurídico, permitindo que o setor dite as próprias regras do jogo. Essa modalidade de acumulação substituiu o capital industrial e aprofundou a crise social e econômica (ALMEIDA, 2016, p.179-197).

Não parece haver controvérsia quanto à necessidade de intervenção do Estado quando as coisas vão mal. O economista Jean Tirole (2014, p. 37) afirma que existem duas razões principais para que haja regulação do sistema financeiro mundial. A primeira é pela alta interconexão das instituições financeiras, em um mercado imperfeitamente competitivo, que atuam por meio de complexas operações de empréstimos. A insolvência de uma instituição pode resultar na queda de um castelo de cartas, como ocorreu na crise de 2008.

A segunda razão seria o fato de os mantenedores da base do sistema serem consumidores comuns, como por exemplo, pensionistas e pequenos investidores, em uma relação assimétrica com os agentes financeiros. A falta de informação do consumidor pode não só dificultar a avaliação e monitoramento da saúde financeira dos agentes do sistema bancário, como também conduzir a pânicos financeiros que tragam prejuízos para todo o sistema. Assim, algumas garantias de regulação são necessárias para garantir tanto o sistema como o consumidor.

Um tema recorrente para Tirole é a necessidade de se pensar uma regulação equilibrada do sistema financeiro que permita uma avaliação econômica ex ante da alocação eficiente dos recursos para se evitar uma intervenção ex post no sistema. Uma política de resgate garantido (bail out) pode levar a uma conduta de risco moral, em 
que as instituições financeiras arrisquem ainda mais por saberem que o socorro estatal está garantido. Assim, o papel do regulador estaria em restringir a alavancagem e o cálculo de risco das instituições financeiras, mitigando os problemas de risco moral e de seleção adversa que podem ocasionar as crises.

No caso brasileiro, a Constituição Federal, em seu artigo 192, determina que o papel do regulador é o de estruturar o sistema financeiro nacional de forma a promover o desenvolvimento equilibrado do país, bem como servir aos interesses da coletividade. No entanto, é fato que os altos juros de financiamento e as burocracias impostas aos processos aduaneiros constituem umas das maiores barreiras ao desenvolvimento nacional, além de pressionar a dívida pública, hoje na ordem de 74\% do PIB.

Certamente o papel do Estado tem se expandido nos países capitalistas. Mesmo nos Estados Unidos, o Estado tem assumido uma posição protagonista no financiamento de pesquisas, principalmente quando envolvem ciência, tecnologia e inovação. Richard Nelson assinala a importância de o Estado atuar na coordenação dos esforços nacionais considerados estratégicos. $\mathrm{O}$ autor diferencia três grupos de programas governamentais: o que busca o avanço do conhecimento em determinados campos científicos; o de responsabilidade operacional e, portanto, necessidade de novos e melhores equipamentos; e o de satisfazer as necessidades de curto prazo de um setor ou um grupo, por exemplo, o agrícola. Na realidade americana, diz o autor, o Estado é a principal fonte de financiamento das pesquisas universitárias, laboratórios e instituições de pesquisa. Além disso, é forte o financiamento governamental referente a encomenda de produtos para determinados setores ou para resolver problemas específicos de áreas sensíveis, como a da Defesa nacional (NELSON, 2006, p. 89-139).

De todo o exposto, pode-se concluir que a intervenção estatal pode e deve ocorrer, mas para a persecução dos objetivos nacionais e apenas na medida a alcançar esses objetivos.

\section{PARTE III - O EXEMPLO DA CUltura}

Um exemplo de intervenção estatal equivocada é o da utilização da renúncia fiscal em favor da função orçamentária ligada à Cultura. Há uma nítida acomodação dos interesses de parte da comunidade cultural pelo poder público e político, em virtude do forte engajamento político de alguns artistas, ora em apoio a alguns políticos, ora em repúdio a outros. Também o poder de captura é alto, uma vez que membros da comunidade política não raro ocupam cargos de confiança no Executivo (BRASIL, 2018).

O Ministério da Cultura é gestor do Programa Nacional de Apoio à Cultura (Pronac), que adota o Incentivo Fiscal a Projetos Culturais (renúncia fiscal chamada de mecenato). Em anos mais recentes, a renúncia para o setor cultural aumentou a cada 
ano, chegando a 1,7 bilhão em 2017 (vide tabela 4). Como já registrado, esses recursos são gastos tributários que não integram o orçamento da União. $\mathrm{O}$ incentivo fiscal da Lei 8.313/91, mais conhecida por Lei Rouanet, é concedido sem contrapartida financeira, bastando ao proponente apresentar uma prestação de contas ao final do projeto, com o fim de comprovar a realização e a correta utilização dos recursos públicos.

Tabela 2. Gastos tributários - Projeções LDO 2017 (unidade: R\$ 1,00)

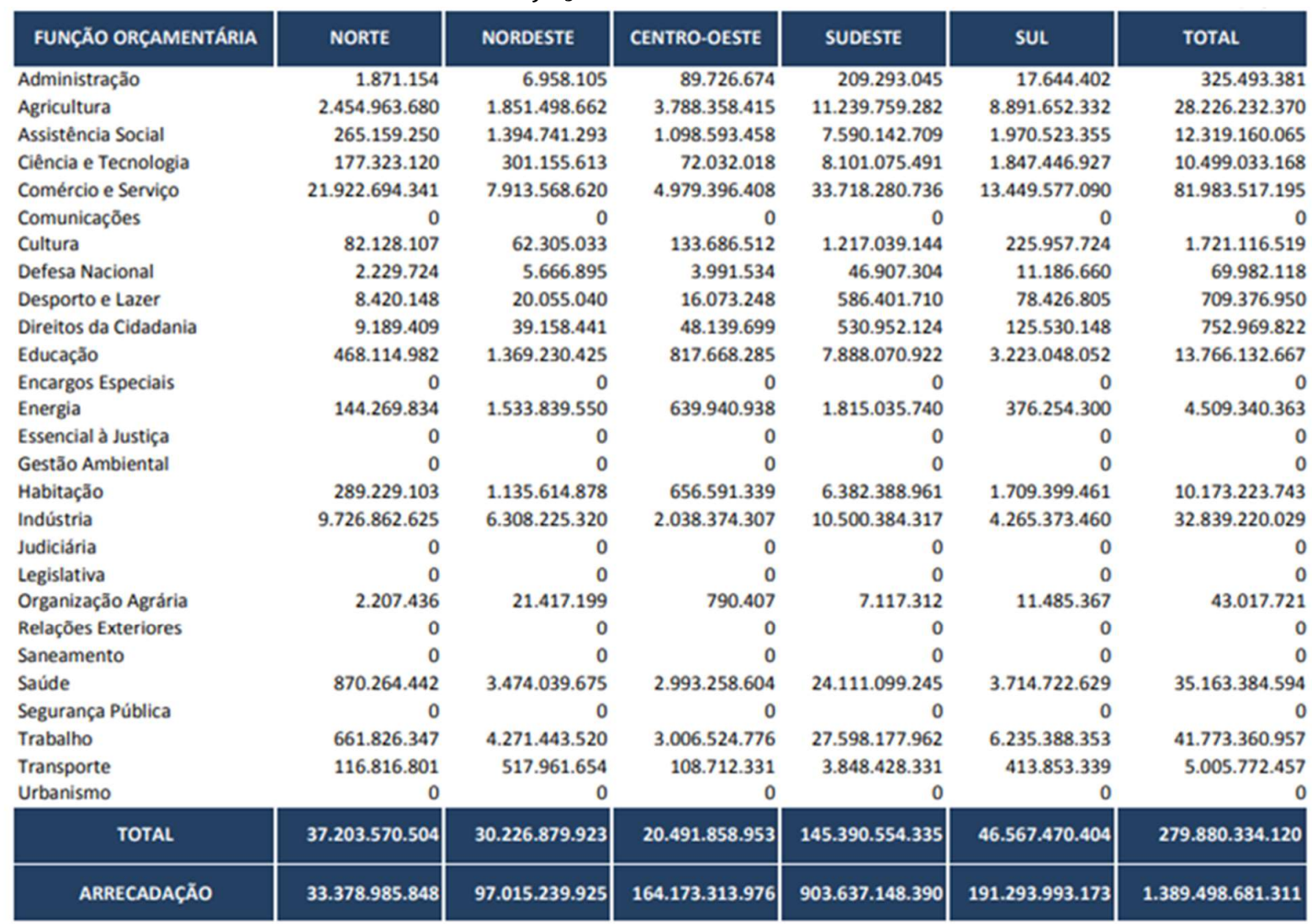

Fonte: Ministério da Fazenda, 2018.

Registra-se a ausência de um corpo burocrático com robustez suficiente para acompanhar e verificar as prestações de contas, tanto para a análise do resultado quanto para a correta utilização dos recursos públicos (BRASIL, 2015b). Problemas de gestão e de baixa capacidade operacional das unidades levaram ao acúmulo de quase vinte mil processos sem verificação da utilização dos recursos públicos, entre os anos de 1997 e 2017. Os 14.955 processos anteriores a 2011 foram denominados passivo (BRASIL, 2018). 
Por esse motivo, foi necessária a contratação de uma força-tarefa de 114 servidores temporários para a análise físico-financeira desses processos (BRASIL, 2011). Em poucos meses de trabalho, constatou-se que os erros na execução dos projetos levariam à reprovação de quase $80 \%$ das prestações de contas. Assim, após fortes pressões dos proponentes culturais, foi elaborada a Portaria MinC n. 86/2014, que relativizava os critérios de avaliação, customizando o processo de análise de modo a diminuir o número de reprovações para menos de $20 \%$.

Como se não bastasse a política de resgate aos proponentes, que pode levar a condutas de risco moral, a concentração dos recursos públicos de renúncia do setor cultural é de mais de $80 \%$ nas regiões sudeste e sul do país, em muitos casos para atender projetos com forte retorno comercial. Os dados fornecidos pelo Ministério da Fazenda comprovam a má distribuição dos recursos públicos:

Tabela 3. Gastos Tributários - Projeções PLOA 2018 (razões percentuais)

\begin{tabular}{|c|c|c|c|c|c|c|}
\hline FUNÇÄO ORÇAMENTÁRIA & NORTE & NORDESTE & CENTRO-OESTE & SUDESTE & sut & TOTAL \\
\hline Agricultura & 8,02 & 6,15 & 12,69 & 41,68 & 31,47 & $100, \infty$ \\
\hline Ciência e Tecnologia & 1,85 & 2,29 & 0,58 & 77,99 & 17,29 & 100,00 \\
\hline Comércio e Serviço & 24,01 & 10,98 & 6,42 & 41,63 & 16,95 & $100, \infty$ \\
\hline Comunicações & 63,64 & $0, \infty$ & 13,63 & 13,63 & $9, \infty 9$ & $100, \infty$ \\
\hline Desporto e Lazer & 2,36 & 3,90 & 1,81 & 76,62 & 15,31 & $100, \infty$ \\
\hline Direitos da Cidadania & 1,30 & 7,94 & 4,08 & 69,89 & 16,80 & $100, \infty$ \\
\hline Educaçăo & 3,96 & 11,91 & 7,48 & 57,23 & 19,42 & $100, \infty$ \\
\hline Encargos Especiais & - & - & - & - & - & - \\
\hline Energia & 0,85 & 32,01 & 15,67 & 39,26 & 12,20 & $100, \infty$ \\
\hline Essencial à Justiça & . & . & . & . & $\cdot$ & - \\
\hline Legislativa & - & - & - & - & - & - \\
\hline Organização Agrária & 5,13 & 49,79 & 1,84 & 16,55 & 26,70 & 100,00 \\
\hline Relaçōes Exteriores & 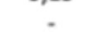 & . & - & 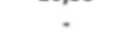 & 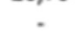 & 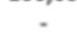 \\
\hline Saneamento & 100,00 & $0, \infty$ & $0, \infty$ & 0,00 & $0, \infty$ & $100, \infty$ \\
\hline Saúde & 2,35 & 9,41 & 8,81 & 68,74 & 10,69 & 100,00 \\
\hline Segurança Pública & . & - & 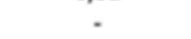 & - & - & - \\
\hline Trabalho & 2,00 & 10,71 & 7,51 & 64,88 & 14,91 & $100, \infty$ \\
\hline Transporte & 2,76 & 8,04 & 1,66 & 77,63 & 9,91 & $100, \infty$ \\
\hline Urbanismo & . & - & 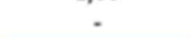 & - & . & - \\
\hline TOTAL & 11,86 & 11,58 & 7,48 & 52,48 & 16,60 & 100,00 \\
\hline
\end{tabular}

Fonte: Ministério da Fazenda, 2018 (BRASIL, 2018a). 
Embora a Lei Rouanet tenha como proposta a canalização de recursos para facilitar o acesso a fontes de cultura e estimular a regionalização, é certo que esse objetivo não foi atingido. O dinamismo econômico das regiões sudeste e sul provoca não só movimentos de migração e de concentração de capital e investimentos, mas também uma diminuição do investimento nas regiões com menor robustez econômica, o que agrava as disparidades regionais e não concede um tratamento equânime ao conjunto das expressões culturais brasileiras.

Esse é um exemplo de uso inadequado do mecanismo da renúncia fiscal, que gera sobretudo uma perda de competitividade que reforça a baixa permeabilidade global do país. A política pública deixa de alcançar o fim redistributivo e de alocação ótima dos recursos e passa a atender grupos mais estruturados e capazes de defender seus interesses. Os princípios da eficiência e da efetividade ficam comprometidos, reforçando mesmo a desigualdade na distribuição da riqueza.

Mostra-se necessária a avaliação da qualidade da política pública, instituída por meio do Pronac, observando indicadores e métricas apropriadas para verificar os atributos da relevância, objetividade, economicidade, custo-benefício, confiabilidade e, sobretudo, a efetividade da aplicação desses recursos públicos. A participação pública deve ser estratégica para promover o atingimento dos objetivos constitucionais por exemplo, de diversidade, descentralização universalização e difusão dos bens culturais, "para o desenvolvimento humano, social e econômico" (art. 216).

Outro aspecto que merece destaque é a necessidade de se buscar a transversalidade das políticas públicas, de modo a se evitar sobreposição de recursos e objetivos, permitindo a otimização de tempo, de recursos humanos e de verbas públicas com o fim de se alcançar a emancipação dos setores envolvidos. A adoção dessa estratégia permitirá alcançar o desenvolvimento regional de que tratam os arts. 43, 151, inciso I, 165, §1ํㅜ 221, inciso III, da Constituição Federal. O Tribunal de Contas da União, ao analisar a necessidade de implantação de um Plano Nacional de Desenvolvimento Regional, concluiu que

Somente por meio desses aprimoramentos será possível atacar efetivamente a questão da desigualdade regional, atendendo a dois propósitos fundamentais e complementares: a equidade na produção e na distribuição das riquezas nacionais, de um lado, e a ampliação do desenvolvimento do país, de outro. Nesse sentido, torna-se imprescindível valer-se do potencial das áreas apartadas do desenvolvimento nacional, considerando as vantagens competitivas que podem advir da inclusão das suas forças naturais, econômicas, sociais e culturais. As políticas públicas devem ser capazes de aproveitar os pontos fortes de cada território, a fim de que possam contribuir melhor para o desenvolvimento sustentável e equilibrado de todo o país (BRASIL, 2015b). 
Destarte, a própria Constituição Federal estabelece a direção que as políticas públicas devem tomar, orientadas a uma missão, qual seja, a de fomentar a regionalização da produção cultural, artística e jornalística com o fim precípuo de desenvolver e reduzir as desigualdades regionais, de forma alguma ajudando a ressaltá-las, como no caso em tela.

\section{CONClusão}

O teto dos gastos públicos, instituído pela EC 95/2016, pressiona pela utilização alternativa de mecanismos classificados como gastos tributários, entre eles, a renúncia fiscal. A utilização desmedida de políticas econômicas de renúncia fiscal gera uma forte pressão sobre a dívida pública. Apesar das recomendações dos organismos internacionais, o país ainda precisa avançar no controle mais acurado dos resultados das políticas públicas econômicas. São escassos os estudos científicos e oficiais que analisem o reflexo do gasto tributário via renúncia fiscal sobre as receitas orçamentárias. Não se afere com precisão a arrecadação potencial e o quanto se deixa de arrecadar para, ao final, verificar o efeito multiplicador dessas políticas econômicas sobre o PIB e o desenvolvimento econômico. Em outras palavras, é necessário que se analise se as externalidades positivas desses gastos públicos compensam a pressão sobre a agenda fiscal que resulta da ausência de integralização dessas receitas tributárias no orçamento fiscal.

Constata-se que, embora a renúncia fiscal possa ser utilizada como mecanismo temporário para corrigir distorções econômicas e sociais regionalizadas, o que ocorre é uma centralização dos recursos públicos em regiões onde já se pode observar o dinamismo econômico, em detrimento de outras regiões que ainda não apresentam desenvolvimento econômico significativo. Embora essa transferência de recursos possa ser em parte justificada pelo contexto de crise nos últimos anos, que pode exigir medidas keynesianas, a renúncia fiscal é um mecanismo que precisa ser entendido como excepcional. Não deve gerar dependência, mas auxiliar para que se alcance autonomia do setor privado. Portanto, caberia se pensar mudanças e diminuição gradual e constante da utilização dessa política para alguns setores.

A renúncia fiscal deve ser utilizada prioritariamente para fomentar o investimento em regiões com insuficiência de investimentos e com maiores índices de desigualdade. Nesse caso, sua utilização estaria justificada não só sob a ótica do custo-benefício, mas sob a ótica da equidade e do desenvolvimento socioeconômico. Para as regiões que já apresentam dinamismo, cabe ao Estado adotar outras políticas que estimulem a competitividade, a concorrência, a educação e corrijam distorções no sistema fiscal que possam inibir iniciativas do setor privado que levariam a um maior crescimento 
econômico. Destarte, espera-se do Estado políticas aplicadas que auxiliem a adoção, por exemplo, de tecnologias emergentes e de engenharia da informação, aplicadas à inclusão do país no que se convencionou chamar de Quarta Revolução Industrial, ligada à ideia do movimento global da Indústria 4.0. (Schwab, 2018)

Por fim, cabe ao Estado catalisar as políticas públicas que possam ser executadas de forma sinérgica, de modo a cumprir as diretrizes constitucionais e os objetivos esposados nos incisos do artigo $3^{\mathbf{o}}$ da Constituição Federal. Uma atuação em rede permitiria um adequado aproveitamento dos escassos recursos e poderia alavancar o desenvolvimento do país e a diminuição das desigualdades.

\section{REFERÊNCIAS}

ALMEIDA, Silvio. A intervenção do estado na economia capitalista. In: SIQUEIRA NETO, José Francisco; BERTOLIN, Patrícia Tuma Martins (Org.). O poder econômico e seus limites jurídicos. São Paulo: Mackenzie, 2016.

BAGNOLI, Vicente. Direito econômico. 6. ed. São Paulo: Atlas, 2013.

BANCO MUNDIAL, World Bank Policy Research Working Paper 3927. Maio, 2006. Disponível em <http://documents.worldbank.org/curated/pt/602361468341100836/pdf/wps3927.pdf> Acesso em: 1 mai. 2018.

BANCO MUNDIAL, Dados dos países com alta renda per capita. Disponível em: $<$ https://data.worldbank.org/income-level/high-income>. Acesso em: 24 mai. 2018.

BERCOVICI, Gilberto. Ciência e inovação sob a constituição de 1988. Revista dos Tribunais. São Paulo, fev. 2012, n. 916. p. 267-295.

BERTOLIN, Patrícia; SMANIO, Gianpaolo (Org.). O Direito e as políticas públicas no Brasil. São Paulo: Atlas, 2013.

BRASIL. Lei n. 9.887, de 7 de dezembro de 1999. Altera a legislação tributária federal. Diário Oficial da República Federativa do Brasil, Brasília, DF, 8 dez. 1999. 
BRASIL, Ministério da Transparência e Controladoria-Geral da União. Relatório de Auditoria Anual de Contas CGU n 201503356, 2015 (2015a). Disponível em $<$ https://www.cgu.gov.br/assuntos/auditoria-e-fiscalizacao/pesquisa-de-relatorios> Acesso em: 05 mai. 2018.

BRASIL, Ministério da Transparência e Controladoria-Geral da União. Relatório CGU n. 201503356/2014 UCI Executora: SFC/DRCUT - Coordenação-Geral de Auditoria da Área de Cultura p. 47. 4 Disponível em $<$ https://auditoria.cgu.gov.br/download/7499.pdf>. Acesso em: 3 mai. 2018.

BRASIL, Câmara dos Deputados. Orçamento em Foco. Parâmetros, resultados fiscais e execução. Ano 3, n. 1, 2016. Brasília, DF: Outubro, 2016 (2016a).

BRASIL, Ministério da Fazenda. 2º Orçamento de Subsídios da União. Relatório do Governo Federal sobre os gastos tributários e os benefícios financeiros e creditícios no período de 2003 a 2017. Maio, 2018 (2018a). Disponível em $<$ https://www.fazenda.gov.br/centrais-de-conteudos/publicacoes/orcamento-desubsidios-da-uniao/arquivos/osu_segundaedicao_vfinal.pdf>. Acesso em: 7 mai. 2018.

BRASIL, Ministério da Fazenda. Secretaria do Tesouro Nacional. Relatório de Avaliação de Receitas e Despesas Primárias. Extemporâneo de Dezembro, 2017 (2017a).

BRASIL, Receita Federal do Brasil. Evolução dos Gastos Tributários: Subsídios da União e Qualidade do Gasto Público. Apresentação feita pelo então Secretário da Receita Federal do Brasil, Sr. Jorge Rachid Outubro, 2017 (2017b). Disponível em $<$ http://idg.receita.fazenda.gov.br/dados/receitadata/estudos-e-tributarios-eaduaneiros/gastos-tributarios-trabalhos/gastos-tributarios-capa>. Acesso em 5 ago. 2019.

BRASIL, Receita Federal do Brasil. Previsões da PLOA 2018 (2018b). Disponível em $<$ https://idg.receita.fazenda.gov.br/dados/receitadata/renuncia-fiscal/previsoesploa/arquivos-e-imagens/texto-dgt-ploa-2018-arquivo-final-para-publicacao.pdf>. Acesso em: 1 mai. 2018. 
BRASIL, Renúncia $\quad$ Fiscal. $\quad$ Disponível em $<$ http://idg.receita.fazenda.gov.br/dados/receitadata/renuncia-fiscal/previsoesploa/dgt-ploa-2017-versao-1-1.pdf>. Acesso em: 2 mai. 2018.

BRASIL, TRIBUNAL DE CONTAS DA UNIÃO. Lei Orgânica n. 8443, de 16 de julho de 1992. Regimento Interno de 2 de janeiro de 2015.

BRASIL, TRIBUNAL DE CONTAS DA UNIÃO. Acórdão TCU 747/2010, item 6.11. Documento interno.

BRASIL, TRIBUNAL DE CONTAS DA UNIÃO. Relatório de levantamento de auditoria - Processo no TC 018.259/2013-8. 2014 (2014a). Disponível em: $<$ http://www.tcu.gov.br/Consultas/Juris/Docs/judoc/Acord/20140516/AC_1205_16_14 _P.doc>. Acesso em: 02 maio 2018.

BRASIL, TRIBUNAL DE CONTAS DA UNIÃO. TCU TC 014.981/2017-3 (2017c).

Disponível em <https://pesquisa.apps.tcu.gov.br/\#/pesquisa/acordao-completo> Acesso em 05 maio 2018.

BRASIL, TRIBUNAL DE CONTAS DA UNIÃO. TCU Acórdão 1.385/2011. Disponível em <https://pesquisa.apps.tcu.gov.br/\#/pesquisa/acordao-completo> Acesso em 05 Mai.2018.

BRASIL, TRIBUNAL DE CONTAS DA UNIÃO. TCU TC 020.126/2015-8 (2015b). Disponível em <https://pesquisa.apps.tcu.gov.br/\#/pesquisa/acordao-completo> Acesso em 05 maio 2018.

BRASIL, Centro de Gestão e Estudos Estratégicos - CGEE. The Brazilian Innovation System. Em Temas Estratégicos para o Brasil. Março, 2016 (2016b). Disponível em $<$ https://www.cgee.org.br/documents/10195/1774546/Sistema_Brasileiro_de_Inovacao -Mazzucato_Penna-Sumario_Executivo.pdf>. Acesso em: 12 mai. 2018.

BRASIL, Lei $\mathrm{n}^{\circ}$ 8.313, de 23 de dezembro de 1991. Restabelece princípios da Lei $\mathrm{n}$. 7.505, de 2 de julho de 1986, institui o Programa Nacional de Apoio à Cultura (Pronac) e dá outras providências. 
BRASIL, Portaria MinC n 86, de 26 de agosto de 2014 (2014b). Estabelece procedimentos para análise de prestação de contas de projetos culturais pendentes de conclusão até 31 de dezembro de 2011, relativos ao mecanismo de incentivos fiscais do Programa Nacional de Apoio à Cultura - PRONAC.

BULOS, Uadi Lammêgo. Curso de direito constitucional. 10. ed. São Paulo: Saraiva, 2017.

DEL MASSO, Fabiano. Direito econômico. Rio de Janeiro: Campus, 2007.

FMI, Fundo Monetário Internacional. Manual de Transparência Fiscal 2007. Disponível em: <https://www.imf.org/external/np/fad/trans/por/manualp.pdf>. Acesso em: 29 abr. 2018.

FMI, Working Paper. Estimating the Base of the Value-Added Tax (VAT) in Developing Countries: The problem of Exemptions. G.A. Mackenzie, authorized for distribution. WP/91/21. February, 1991. Disponível em: $<$ https://www.imf.org/en/Publications/WP/Issues/2016/12/30/Estimating-the-Base-ofthe-Value-Added-Tax-VAT-in-Developing-Countries-The-Problem-of-897>. Acesso em: 29 abr. 2018.

GASPARINI, Diógenes. Direito administrativo. 16. ed. São Paulo: Saraiva, 2010.

GIAMBIAGI, Fábio; ALÉM, Ana Claudia. Finanças públicas. 4. ed. Rio de Janeiro: Campus, 2011.

HILL, Michael; HUPE, Peter. Implementing public policy: an introduction to the study of operational governance. 3. ed. London: Sage Publications, 2014.

HOWLETT, Michael; RAMESH, M.; PERL, Anthony. Política pública: seus ciclos e subsistemas - uma abordagem integral. Rio de Janeiro: Elsevier, 2013.

MAZZUCATO, Mariana. O Estado empreendedor. São Paulo: Schwarcz, 2015.

MINARIK, Joseph. Tax Expenditures in OECD countries. Meeting of Senior Budget Officials. OECD, Paris, jun., 2009. 
MUSGRAVE, Richard; MUSGRAVE, Peggy. Finanças públicas - teoria e prática. Rio de Janeiro: Campus, 1980.

NELSON, Richard. As fontes do crescimento. Campinas: Unicamp, 2006.

OCDE, Tax Expenditures in OECD Countries - OECD ISBN: 9789264076891. Publicado em $27 \quad$ Jan. $2010 . \quad$ Disponível em $<$ https://www.oecd.org/gov/budgeting/taxexpendituresinoecdcountriesoecdpublication.htm\#toc>. Acesso em: 23 maio 2018.

PALUDO, Augustinho. Orçamento público. 5. ed. Rio de Janeiro: Método, 2015.

PETERS, Guy. The politics of public sector coordination. Kansas City: Kansas Press, 2015.

PINTO, Felipe; SANTOS, Larissa. A atuação estatal desempenhada para fomentar o desenvolvimento brasileiro. Revista Justiça do Direito. 2017, v. 31, n. 1, p. 170-187.

POLANYI, Karl. A grande transformação. Rio de Janeiro: Campus, 2000.

POLLITT, Christopher e BOUCKAERT, Geert. Public management reform: a comparative analysis. New York: Oxford University Press, 2000.

SCAFF, FERNANDO; HORVATH, Estevão. Direito financeiro, econômico e tributário. São Paulo: Quartier Latin, 2014.

SCHWAB, Klaus. A Quarta revolução Industrial. São Paulo: Edipro, 2018.

SWIFT, Zhicheng Li. Managing the Effects of Tax Expenditures on National Budgets. World Bank Policy Research Working Paper 3927, May 2006. Disponível em: https://ssrn.com/abstract=917498 Acesso em: 23 maio 2018.

TIROLE, Jean. Market power and regulation. Stockhholm: Royal Swedish Academy of Science, 2014. 
A EFICIÊNCIA DO GASTO TRIBUTÁRIO E A UTILIZAÇÃO DAS POLÍTICAS DE RENÚNCIA FISCAL NA CULTURA

TORRES, Heleno. Direito constitucional financeiro - Teoria da Constituição Financeira. São Paulo: Revista dos Tribunais, 2014. 